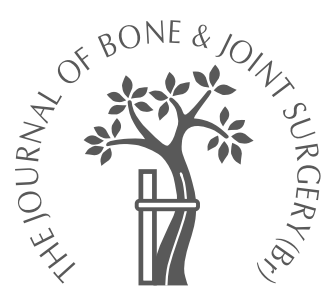

S. Jacobsen,

S. Sonne-Holm,

K. Søballe,

P. Gebuhr,

B. Lund

From Hvidovre University Hospital

of Copenhagen, Copenhagen, Denmark

\title{
Joint space width in dysplasia of the hip
}

\author{
A CASE-CONTROL STUDY OF 81 ADULTS FOLLOWED FOR \\ TEN YEARS
}

In a longitudinal case-control study, we followed 81 subjects with dysplasia of the hip and 136 control subjects without dysplasia for ten years assessing radiological evidence of degeneration of the hip at admission and follow-up. There were no cases of subluxation in the group with dysplasia. Neither subjects with dysplasia nor controls had radiological signs of ongoing degenerative disease at admission. The primary radiological discriminator of degeneration of the hip was a change in the minimum joint space width over time. There were no significant differences between these with dysplasia and controls in regard to age, body mass index or occupational exposure to daily repeated lifting at admission.

We found no significant differences in the reduction of the joint space width at follow-up between subjects with dysplasia and the control subjects nor in self-reported pain in the hip. The association of subluxation and/or associated acetabular labral tears with dysplasia of the hip may be a conditional factor for the development of premature osteoarthritis in mildly to moderately dysplastic hips.

Since Wiberg's ${ }^{1}$ thesis on the subject in 1939 , it has been accepted that residual dysplasia of the hip predisposes to osteoarthritis (OA). Reduction in the load-bearing areas in dysplastic hips causes degeneration ${ }^{2-9}$ which is often preceded by labral tears and other soft-tissue lesions. While premature OA develops in subluxed hips, the extent and rate at which it occurs in moderate dysplasia of the hip is uncertain. There have been only two longitudinal studies with small numbers of patients. ${ }^{10,11}$

Evidence from cross-sectional studies is contradictory because the morphology and description of the condition have been inconsistently defined and the prevalence of dysplasia of the hip in the general population has not been estimated. Several studies have been based on pelvic radiographs obtained for unrelated conditions. ${ }^{12-23}$

Over the last decade, pelvic realignment osteotomy has been increasingly performed to prevent the development of OA in dysplastic hips. ${ }^{24-}$ 27 This has stimulated our interest in the subject.

We have followed 81 subjects with dysplasia of the hip for ten years to assess radiological evidence of degeneration of the hip.

\section{Patients and Methods}

The subjects were recruited from the Third Copenhagen City Heart study, the osteoarthritis cohort (CCHS) of 1991 to 1994.
The CCHS is a longitudinal survey of an adult, Caucasian cohort from the county of Osterbro in Copenhagen by random socialsecurity number. The survey has registered life style and health variables since $1976 .^{28}$

Between 1991 and 1994, anteroposterior (AP) weight-bearing pelvic radiographs were recorded in 4151 participants. There were 1533 men of mean age 62 years (23 to 93) and 2618 women of mean age 65 years (22 to 92). The radiographs were obtained in the standing position with the feet pointing straight forward and the lower limbs in neutral abductionadduction. The $\mathrm{x}$-ray beam was centered two finger breadths above the symphysis pubis in the midline and the tube-to-film distance was $120 \mathrm{~cm}$. Two radiographers obtained all radiographs.

Radiological features of OA of the hip. The minimum width of the joint space was measured at the lateral margin of the subchondral sclerotic line ('the sourcil'), at the apical transection of the weight-bearing surface by a vertical line through the centre of the femoral head, and at the medial margin of the weight-bearing surface bordering on the fovea. The minimum width was defined as the smallest of the three measurements. The thickness of subchondral sclerosis was measured at one point, and subchondral cysts and osteophytes were recorded (Fig. 1). One observer (SJ) performed all the 


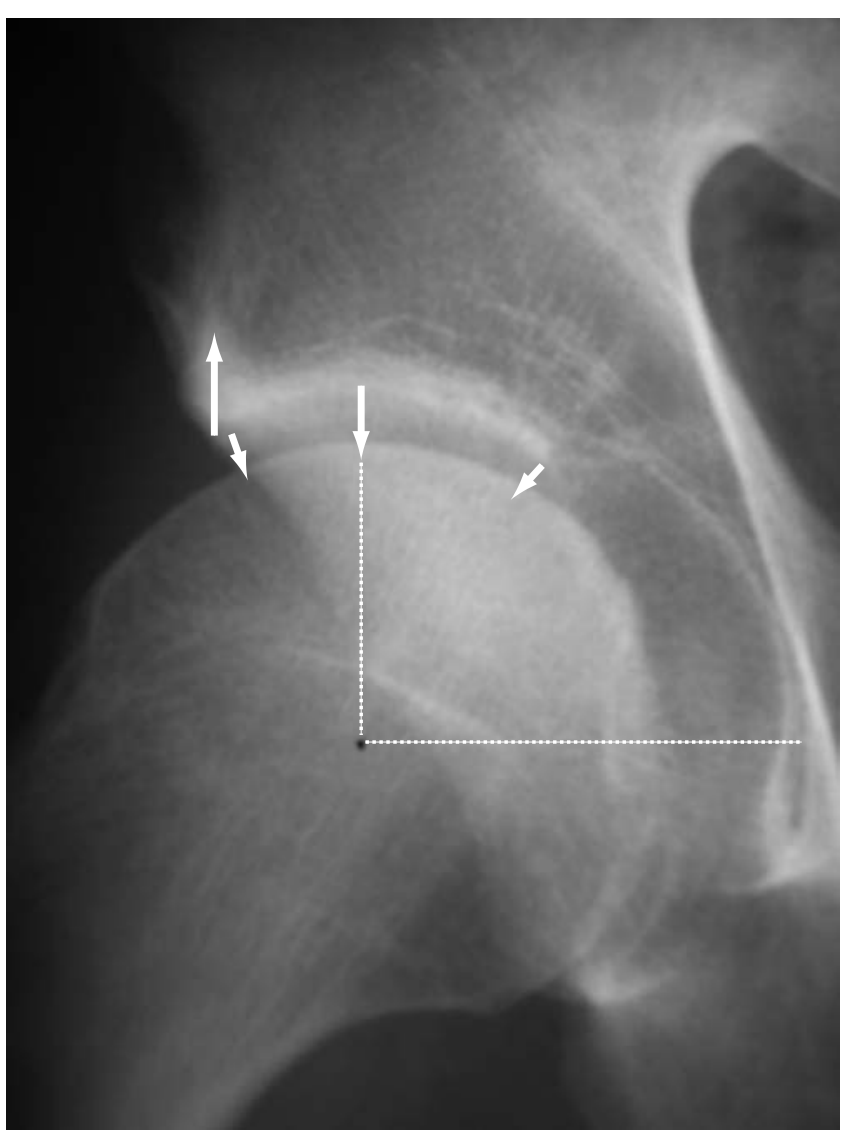

Fig. 1

Measurements of joint space width in the hip.

measurements using a $0.1 \mathrm{~mm}$ graded magnifying glass (Peak, Tokyo, Japan).

Radiological features of dysplasia of the hip. Acetabular morphology was assessed by the acetabular depth ratio of
Murray $^{29}$ and Stulberg and Harris ${ }^{30}$ (Fig. 2). The cut-off value was set at $\leq 250 \%$. Containment of the femoral head was assessed by the centre-edge (CE) angle of Wiberg ${ }^{1}$ with a cut-off value set at $\leq 20^{\circ}$ (Fig. 2b) and the femoral head extrusion index of Heyman and Herndon ${ }^{31}$ with a cut-off value set at $\geq 20 \%$ (Fig. $2 \mathrm{c}$ ). The lateral margin of the sourcil was used to designate the lateral acetabular rim in relevant measurements. Shenton's line was evaluated. Pelvic rotation during radiography was assessed using the foramen obturator index of Tönnis ${ }^{32}$ in which the maximum horizontal width of the right obturator foramen was divided by that of the left.

Physical and occupation parameters. At the CCHS examinations of 1991 to 1994 , the weight and height of all participants were recorded and the body mass index (BMI/kg/ $\mathrm{m}^{2}$ ) calculated. The CCHS questionnaires recorded occupation since leaving school and for each occupation registered the frequency of different levels of lifting during a typical working day. The questions were formulated along the guidelines of The Danish National Board of Industrial Injuries, using the following categories: 1) primarily seated occupation; 2) standing, walking occupation, no repeated lifting; 3) daily repeated lifting equivalent to $50 \times 20 \mathrm{~kg}$ or $20 \times 50 \mathrm{~kg}$; 4) repeated daily lifting equivalent to 50 to 100 x $20 \mathrm{~kg}$ or 20 to 50 x $50 \mathrm{~kg}$; 5) repeated daily lifting equivalent to 100 to $250 \times 20 \mathrm{~kg}$ or 50 to $100 \times 50 \mathrm{~kg}$; and 6) repeated daily lifting equivalent to 250 to $500 \times 20 \mathrm{~kg}$ or 100 to 250 x $50 \mathrm{~kg}$.

Exclusion criteria of radiography. In an earlier cadaver study we found that pelvic rotation had a significant influence on the radiological indices of dysplasia of the hip. ${ }^{33}$ To stay inside $\pm 3^{\circ}$ of error of measurement of the CE angle, the foramen obturator index inclusion limits of 0.7 to 1.8 were applied to the radiographs. Furthermore, radiographs in which measurements were inaccurate because of obesity were omitted.

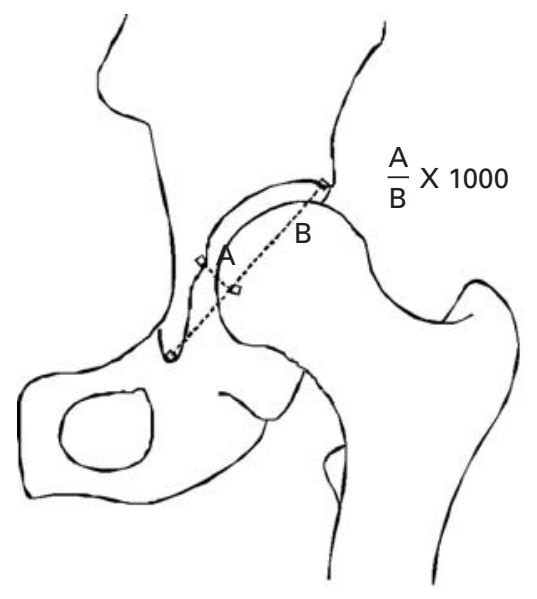

Fig. 2a

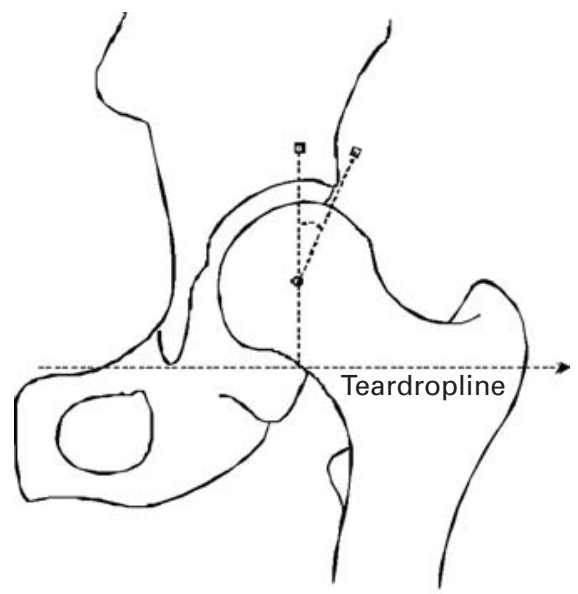

Fig. 2b

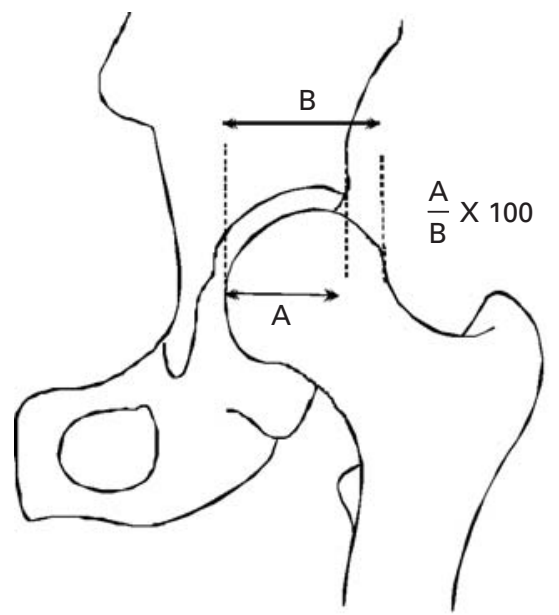

Fig. 2c

Diagrams showing a) the acetabular depth ratio (ADR); b) the CE angle of Wiberg and c) the femoral head extrusion index (FHEI). 
The application of foramen obturator index limits of 0.7 to 1.8 excludes 188 (4.5\%) of the 4151 of the CCHS pelvic radiographs. Applying individual exclusion criteria to the CCHS cohort resulted in the final inclusion of 1429 men with a mean age of 61 years ( 23 to 93), and 2430 women with a mean age of 61 years (22 to 92 years).

Exclusion criteria of subjects. These were previous surgery to either hip, previous fracture of either hip, treatment of childhood hip disorders and a history of rheumatoid arthritis in any joint.

Case-control study of 2003. The follow-up study was approved by the Ethics Committee of Copenhagen. After preliminary measurements of the pelvic radiographs of 1991 to 1994, 81 subjects ( 27 men, 54 women) with unilateral or bilateral dysplasia of the hip (CE angle $\left.\leq 20^{\circ}\right)$, and still living in Copenhagen, were recruited for the follow-up study. A group of 136 subjects ( 66 men, 70 women) without dysplasia of the hip (bilateral CE angle $\geq 25^{\circ}$ ) consented to act as a control group. Subjects with OA as seen on the initial pelvic radiographs were excluded. The minimum joint space width measurement was $>2.0 \mathrm{~mm}$ and maximum subchondral sclerosis $5.67 \mathrm{~mm}$ in men and $5.37 \mathrm{~mm}$ in women. There were no subchondral cysts or osteophytes in the group with dysplasia of the hip or the control group.

Clinical examination. At the follow-up examination the participants were assessed by the Hospital for Special Surgery score (HSS $)^{34,35}$ and the intensity of pain by a visual analogue scale (VAS) during the 12 months before investigation. The maximum score on the HSS is 40 . The VAS ranged from 0 (no pain) to 10 (unbearable pain). The categories of pain included groin, gluteal, hip, radicular, lower back, morning stiffness and pain, and during sleep. The weight and height were recorded and the BMI calculated.

Radiological examination at follow-up. The same radiological technique as in 1991 to 1994 was used at the follow-up in 2003. Any difference in magnification between the two sets of radiographs was standardised by comparing the radius of the femoral head in the original pelvic radiographs with that at follow-up. The same radiological indices of dysplasia and OA were used in both sets. All radiographs were taken between August and September 2003.

Reproducibility. Intra-observer reproducibility of measurements of joint space width and parameters of dysplasia was assessed by blinded re-reading of a subset of 50 CCHS subjects, and 50 follow-up radiographs four weeks after the first reading (SJ), using the method of Bland and Altman. ${ }^{36}$ Statistical analysis. The correlation between the minimum joint space width and the degree of dysplasia were analysed by Spearman's correlation coefficient. Paired sampled $t$-tests estimated differences between subjects with dysplasia of the hip and the control group in regard to age, BMI, occupation, the minimum joint space width and degree of dysplasia of the hip at the CCHS examination of 1991 to 1994 and at follow-up examinations. VAS scores for pain and HSS scores were compared by paired $t$-tests. The

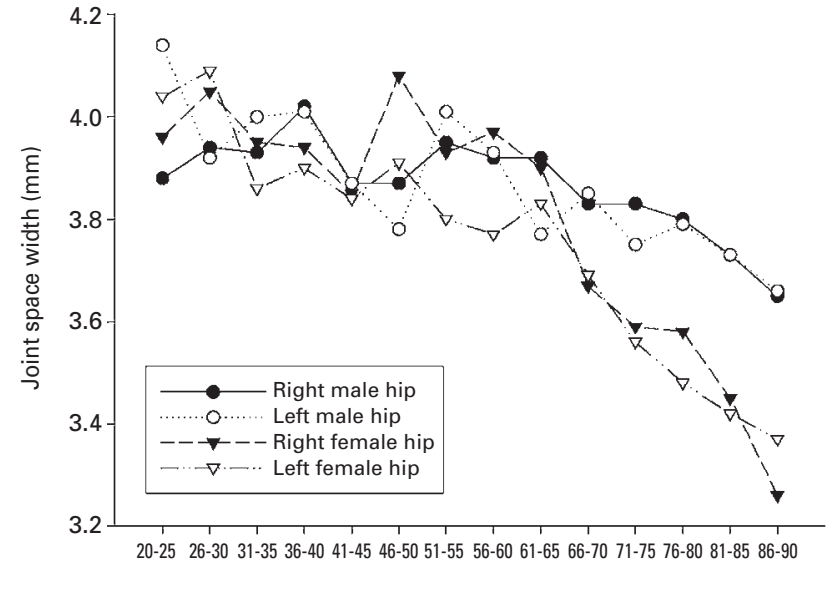

Age groups (yrs)

Fig. 3

The association between minimum joint space width and age in normal subjects.

changes in minimum joint space width were assessed by one-tailed $t$-tests and the total changes in minimum joint space width between groups by the Mann-Whitney U test. The risk of developing a pathologically-reduced minimum joint space width, increased subchondral sclerosis, osteophytes or subchondral cysts in the follow-up period in the subjects with dysplasia of the hip and the control group was assessed by the chi-squared test. Significance was set at $\mathrm{p}<$ 0.05 . All statistical analyses were performed by SPSS 11.5 statistical software (SPSS Inc, Chicago, Illinois).

\section{Results}

\section{The CCHS cohort}

Reproducibility. Intra-observer reproducibility was acceptable for measurements of right and left hip centre-edge angles within $2.4^{\circ}$, right and left hip femoral head extrusion index within $2.8^{\circ}$, acetabular depth ratio within $17.3 \%$, minimum joint space width within $0.35 \mathrm{~mm}$. Inter-observer reproducibility was acceptable within $1.8^{\circ}$ for the $\mathrm{CE}$ angle, $2.3 \%$ for femoral head extrusion index, and $15.8 \%$ for acetabular depth ratio and reproducibility of minimum joint space width measurements in follow-up radiographs was acceptable within $0.25 \mathrm{~mm}$.

Prevalence of dysplasia of the hip. The prevalence of dysplasia of the hip in the CCHS cohort was $3.6 \%$ in men and $3.5 \%$ in women if a CE angle of $\leq 20^{\circ}$ was used, $5.6 \%$ in men and $2.3 \%$ in women if an acetabular depth ratio $\leq$ $250 \%$ was used, and $10.7 \%$ in men and $8.4 \%$ in women if a femoral head extrusion index $\geq 20 \%$ was used as a cut-off value for definite dysplasia.

Of the study cohort of 3859 subjects 51 men and 86 women had unilateral or bilateral dysplasia.

Joint space width. The association between joint space width and age in normal subjects is shown in Figure 3. Both genders had a minimum joint space width decrease after the 
Table I Basic values and differences between the control group and subjects with dysplasia of the hip

\begin{tabular}{|c|c|c|c|c|c|c|c|c|c|c|}
\hline \multirow[b]{2}{*}{ Parameter } & \multicolumn{5}{|l|}{ Men } & \multicolumn{5}{|l|}{ Women } \\
\hline & $\begin{array}{l}\text { Control group } \\
\text { (n = 66) Mean }\end{array}$ & $\begin{array}{l}\text { Dysplasia } \\
(n=27) \text { Mean }\end{array}$ & $\begin{array}{l}p \text { value of } \\
\text { difference }\end{array}$ & SED* & $95 \% \mathrm{Cl}^{\dagger}$ & $\begin{array}{l}\text { Control group } \\
(n=70) \text { Mean }\end{array}$ & $\begin{array}{l}\text { Dysplasia } \\
\text { (n = 54) Mean }\end{array}$ & $\begin{array}{l}\text { p value of } \\
\text { difference }\end{array}$ & SED & $95 \% \mathrm{Cl}$ \\
\hline Age (yrs) & 49.9 & 48.6 & 0.62 & 2.6 & -3.9 to 6.5 & 50.5 & 53.1 & 0.21 & 1.9 & -6.3 to 1.3 \\
\hline BMI-1993 $\left(\mathrm{kg} / \mathrm{m}^{2}\right)$ & 26.7 & 26.1 & 0.53 & 0.8 & -1.1 to 2.2 & 25.6 & 24.5 & 0.12 & 0.7 & -0.3 to 3.0 \\
\hline BMI-2003 $\left(\mathrm{kg} / \mathrm{m}^{2}\right)$ & 27.4 & 26.3 & 0.21 & 0.8 & -0.6 to 2.9 & 26.2 & 24.8 & 0.12 & 0.8 & -0.3 to 3.0 \\
\hline HSS $\ddagger$ (max. 40) & 37.3 & 38.1 & 0.25 & 0.7 & -2.2 to 0.6 & 36.8 & 36.4 & 0.65 & 0.8 & -1.3 to 2.0 \\
\hline
\end{tabular}

* SED, standard error of difference

$\dagger 95 \%$ confidence interval of difference

‡ HSS, Hospital for Special Surgery score

Table II. VAS scores of pain and the differences between the control group and subjects with dysplasia of the hip (VAS 1 to 10)

\begin{tabular}{|c|c|c|c|c|c|c|c|c|c|c|c|c|c|c|}
\hline \multirow[b]{3}{*}{ Pain } & \multicolumn{7}{|c|}{ Men } & \multicolumn{7}{|c|}{ Women } \\
\hline & \multicolumn{2}{|c|}{$\begin{array}{l}\text { Control group } \\
(n=27)\end{array}$} & \multicolumn{2}{|c|}{$\begin{array}{l}\text { Dysplasia } \\
(\mathrm{n}=54)\end{array}$} & \multirow[b]{2}{*}{$\begin{array}{l}p \text { value of } \\
\text { difference }\end{array}$} & \multirow[b]{2}{*}{ SEDt } & \multirow[b]{2}{*}{$95 \% \mathrm{Cl}$} & \multicolumn{4}{|c|}{$\begin{array}{l}\text { Control group Dysplasia } \\
(n=70) \quad(n=54)\end{array}$} & \multirow[b]{2}{*}{$\begin{array}{l}p \text { value of } \\
\text { difference }\end{array}$} & \multirow[b]{2}{*}{ SED } & \multirow[b]{2}{*}{$95 \% \mathrm{Cl}$} \\
\hline & Mea & $\%^{*}$ & Mea & $\%$ & & & & Mean & $\%$ & Mean & $\%$ & & & \\
\hline Groin & 0.1 & 4.5 & 0.1 & 3.7 & 0.88 & 0.14 & -0.2 to 0.3 & 0.41 & 15.7 & 0.42 & 16.7 & 0.95 & 0.21 & -0.4 to 0.3 \\
\hline Gluteal & 0.1 & 12.1 & 0.1 & 3.7 & 0.55 & 0.12 & -0.1 to 0.3 & 0.42 & 20.0 & 0.38 & 13.0 & 0.86 & 0.13 & -0.3 to 0.4 \\
\hline Hip & 0.2 & 13.6 & 0.1 & 7.4 & 0.73 & 0.16 & -0.2 to 0.3 & 0.67 & 31.4 & 0.67 & 29.6 & 0.99 & 0.25 & -0.5 to 0.4 \\
\hline Radicular & 0.3 & 21.2 & 0.2 & 11.1 & 0.85 & 0.17 & -0.3 to 0.3 & 0.44 & 31.4 & 0.46 & 22.2 & 0.89 & 0.15 & -0.3 to 0.2 \\
\hline Lower back & 0.6 & 45.5 & 0.6 & 59.3 & 0.93 & 0.19 & -0.4 to 0.3 & 0.70 & 57.1 & 0.55 & 51.9 & 0.25 & 0.12 & -0.1 to 0.3 \\
\hline Morning pain in hips & 0.1 & 7.6 & 0.1 & 3.7 & 0.64 & 0.10 & -0.1 to 0.2 & 0.20 & 14.3 & 0.31 & 14.8 & 0.37 & 0.13 & -0.3 to 0.1 \\
\hline Pain during sleep & 0.0 & 7.6 & 0.1 & 3.7 & 0.83 & 0.09 & -0.2 to 0.17 & 0.20 & 12.9 & 0.18 & 7.2 & 0.94 & 0.12 & -0.2 to 0.2 \\
\hline
\end{tabular}

* total percentage of group with positive VAS scores in pain category

† SED, standard error of difference

Table III. Changes in minimum joint space width in the follow-up period

\begin{tabular}{|c|c|c|c|c|c|c|c|c|}
\hline & \multicolumn{2}{|l|}{ Male right hips } & \multicolumn{2}{|l|}{ Male left hips } & \multicolumn{2}{|c|}{ Female right hips } & \multicolumn{2}{|l|}{ Female left hips } \\
\hline & $\begin{array}{l}\text { Control group } \\
(\mathrm{n}=77)^{*}\end{array}$ & $\begin{array}{l}\text { Dysplasia } \\
(n=16)\end{array}$ & $\begin{array}{l}\text { Control group } \\
(n=72)\end{array}$ & $\begin{array}{l}\text { Dysplasia } \\
(n=21)\end{array}$ & $\begin{array}{l}\text { Control group } \\
(n=90)\end{array}$ & $\begin{array}{l}\text { Dysplasia } \\
(\mathrm{n}=34)\end{array}$ & $\begin{array}{l}\text { Control group } \\
(n=87)\end{array}$ & $\begin{array}{l}\text { Dysplasia } \\
(\mathrm{n}=37)\end{array}$ \\
\hline Joint space width 1993 (mm) & 3.93 & 4.55 & 3.88 & 4.16 & 3.95 & 4.25 & 4.03 & 4.21 \\
\hline Joint space width 2003 (mm) & 3.66 & 4.05 & 3.73 & 3.79 & 3.74 & 3.80 & 3.80 & 3.85 \\
\hline Mean difference (mm) & 0.27 & 0.50 & 0.15 & 0.37 & 0.21 & 0.25 & 0.23 & 0.36 \\
\hline $\mathrm{p}$ value & 0.00 & 0.008 & 0.00 & 0.04 & 0.06 & 0.001 & 0.001 & 0.00 \\
\hline SED† & 0.07 & 0.16 & 0.07 & 0.17 & 0.06 & 0.11 & 0.06 & 0.08 \\
\hline $95 \% \mathrm{Cl}$ & 0.1 to 0.4 & 0.1 to 0.8 & -0.0 to 0.3 & 0.0 to 0.7 & 0.08 to 0.3 & 0.1 to 0.6 & 0.0 to 0.3 & 0.0 to 0.5 \\
\hline
\end{tabular}

* in subjects with unilateral hip dysplasia, the normal hip joint on either side counts as a control hip joint

† SED, standard error of difference

fourth and fifth decades. However, the decrease was progressively steeper in women. Spearman's correlation coefficients of age $v s$ minimum joint space width was $r=-0.06$ in male right hips, and $\mathrm{r}=-0.07$ in male left hips. The corresponding values in women were $\mathrm{r}=-0.17$ in right hips, and $r=-0.18$ in left hips. A lower CE angle was associated with a smaller minimum joint space width in both genders in subjects of $\leq 55$ years of age $(\mathrm{p}<0.0001)$.

The case-control study

Inclusion from the CCHS cohort. All follow-up radiographs were within 0.8 to 1.5 of the foramen obturator index and acceptable. Twenty-seven men with dysplasia attended follow-up examinations $(73 \%$ response rate). Ten had bilateral and 17 unilateral dysplasia. Their mean age was 48.6 years (24 to 79). Sixty-six men of similar age acted as a control group. Fifty-four women with dysplasia attended for follow-up (82\% response rate), of whom 18 had bilateral and 36 unilateral dysplasia of the hip. Their mean age was 53.1 years (25 to 70$)$. Seventy women of mean age 50.6 years (26 to 71 ) acted as a control group. The mean followup period was 10.2 years (9.1 to 11.9 )

Age, BMI, occupation, and HSS score. There were no significant differences in regard to age, the BMI calculated in 1991 to 1994 and 2003, occupational exposure to repeated lifting and the HSS score between patients with dysplasia and the control subjects at follow-up examination (Table I). Morphology of the hip. The CE angle ranged from $6^{\circ}$ to $20^{\circ}$ in dysplastic hips. There were no cases of subluxation of the hip as defined by a break of Shenton's line by more than $5 \mathrm{~mm}$. VAS scores of pain at follow-up. There was no difference in self-reported pain between those with dysplasia and the control group at follow-up (Table II), but, significantly more women reported frequent groin, gluteal and hip pain than men $(p<0.003$ to $p=0.03)$. 


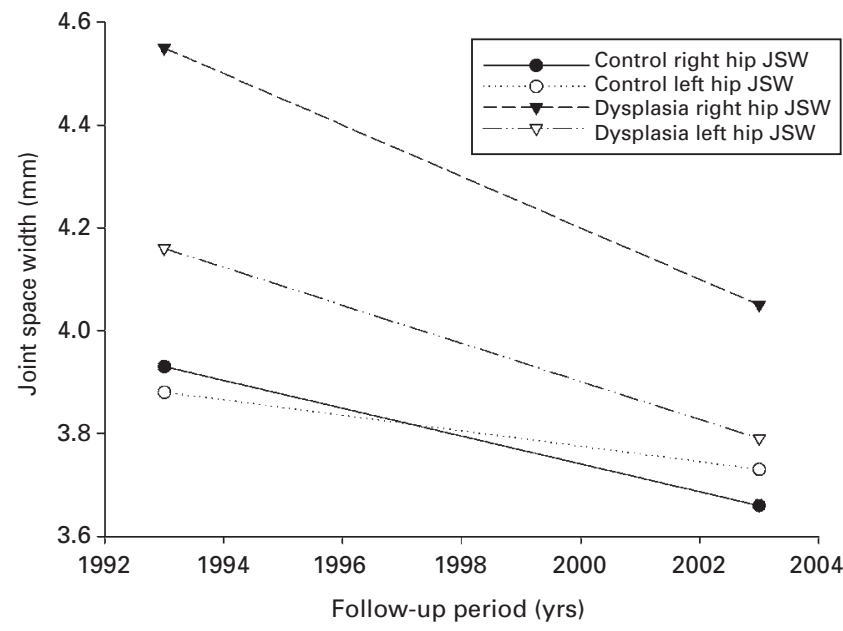

Fig. $4 a$

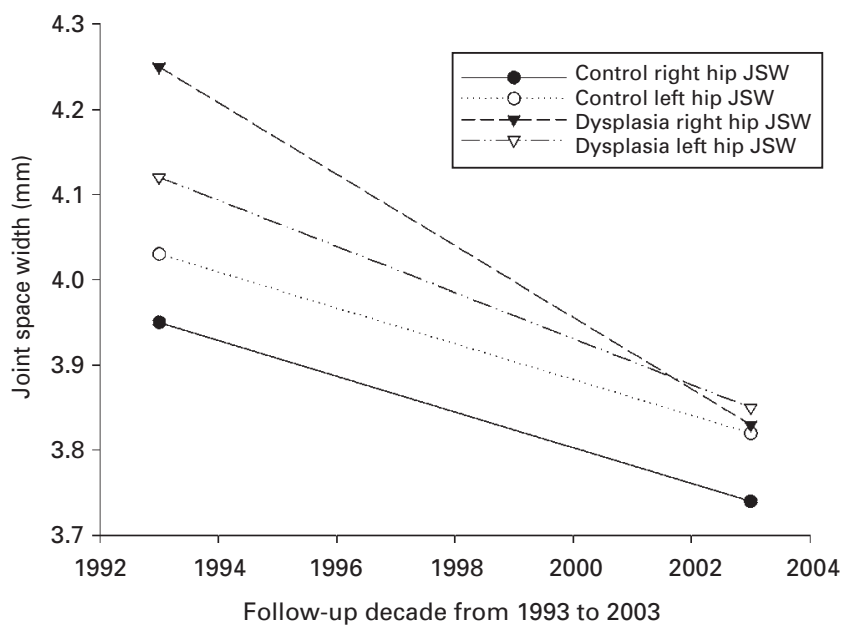

Fig. $4 \mathrm{~b}$

Changes in a) male and b) female hip minimum joint space width (JSW) during the follow-up period.

Changes in joint space width. The minimum joint space width fell significantly during the follow-up period in both those with dysplasia and controls (Fig. 4) (Table III). There was a trend to loss of joint space in the dysplastic group, but this was not statistically significant.

Other radiological features of hip osteoarthritis. There were no significant differences in degeneration in subjects with dysplasia and controls. Four men developed a minimum joint space width $\leq 2.0 \mathrm{~mm}$, which was our principal criterion for definite radiological OA. Three of these were in the control group and one 71-year-old man had dysplasia of the left hip. Two women in the control group developed a minimum joint space width of $\leq 2.0 \mathrm{~mm}$. No participants developed pathologically increased subchondral sclerosis as subchondral cysts, and only one man in the control group developed osteophytes. One woman in the control group also developed osteophytes.

\section{Discussion}

Premature OA of the hip has been attributed to the effects of unrecognised dysplasia. ${ }^{30,37}$ Subluxed hips develop premature degeneration, but the natural course of moderate dysplasia of the hip has not yet been defined. ${ }^{10,11,38}$ During a follow-up period of ten years, we found no significant differences in the reduction of joint space width between normal and dysplastic hips.

In Wiberg's ${ }^{1}$ longitudinal study of 17 dysplastic hips (CE angle $<20^{\circ}$ ) followed for 28 years, OA developed in each case and he found a linear relationship between the CE angle and the age of onset of OA. However, as pointed out by Cooperman et al, ${ }^{10}$ seven of the 17 hips were subluxed with a mean CE angle of $2^{\circ}$ and ten had a mean CE angle of $10^{\circ}$. The mean age of onset of was 57 years in these latter patients. In addition, Wiberg's radiological criteria for OA were not standardised.
Cooperman et $\mathrm{al}^{10}$ performed a similar study in 32 hips of 20 patients followed for 22 years. There were no cases of subluxation. The mean CE angle was $7.4^{\circ}$ (-5 to 20). Jointspace narrowing expressed as a percentage of the normal joint space width determined the radiological outcome of the hip developed in an equal proportion of patients in their sixth and seventh decades as in the fourth and fifth decades of life. Twelve hips developed in the fourth decade, but 11 were without $\mathrm{OA}$ in the fifth decade, and nine in the sixth. ${ }^{10}$

Hasegawa et $\mathrm{al}^{11}$ followed 86 dysplastic hips for a period of 12.8 years. Thirty-three hips developed "early" OA after a mean of 9.2 years, and $66 \%$ of hips "advanced" OA from "early" OA in 7.8 years. A CE angle $<10^{\circ}$, a broken Shenton's line $>10 \mathrm{~mm}$, a femoral head extrusion index $>40 \%$, and an acetabular depth ratio $<200 \%$ were significant predictors of premature OA of the hip. Radiological OA was assigned according to the following criteria: 1) prearthritic, no sclerotic change in the femoral head or the acetabulum; 2) early OA, sclerotic changes without joint-space narrowing; 3) advanced OA, joint-space narrowing; and 4) terminal OA, obliteration of the joint space.

Murphy et a ${ }^{38}$ followed 286 patients who had had total hip arthroplasty performed for OA secondary to dysplasia of the contralateral hip. The follow-up period was not stated. Of these, 74 developed severe OA and 43 patients did not. The remaining 125 patients were excluded because they had not reached 65 years of age and apparently did not develop severe OA. The mean CE angle was $7^{\circ}(-22$ to -28$)$ in those who developed severe OA and $34^{\circ}$ (16 to 49 ) in those who did not. The features of dysplasia were distributed significantly different between the two groups, and the authors concluded that there was a significant relationship between dysplasia and OA of the hip. The radiological outcome measure was the OA score of Kellgren and Lawrence. ${ }^{39}$ 
We have presented these four studies at some length because they illustrate important problems in the epidemiological investigation of OA. First, four different radiological criteria were used to determine definite OA. Composite radiological scores such as that of Kellgren and Lawrence's ${ }^{39}$ as used by Murphy et $\mathrm{al}^{38}$ have significant limitations in hips because of poor reproducibility and inaccurate terminology. ${ }^{16,17,40,41}$ The use of subchondral sclerosis as the critical radiological feature of OA, as in the study of Hasegawa et al, ${ }^{11}$ does not seem to be justified, since it can be regarded as an ageing phenomenon in otherwise healthy joints. Many researchers use the minimum joint space width as the singular feature of radiological degeneration of the hip, ${ }^{13,14,42,43}$ but, to use the percentage of normal joint space width to designate the degree of OA, as in the study of Cooperman et al, ${ }^{10}$ a knowledge of the normal distribution of joint space width in asymptomatic subjects is presupposed. This knowledge is now available ${ }^{19,44}$ which is the reason why we used it in our study.

Secondly, the recording techniques of the source radiographs are poorly described in the studies. In a cadaver study, we have found that pelvic orientation has a significant effect on measurements in dysplastic hips in AP radiographs. ${ }^{33}$

Thirdly, the background incidence of OA of the hip and the influences of age and gender on this incidence have to be taken into consideration when estimating rates of degeneration in longitudinal cohorts with dysplasia of the hip. ${ }^{45-48}$ There were no age- and gender-matched control groups in any of the studies. If dysplasia of the hip causes premature $\mathrm{OA}$ in the young, we found it curious that a group of 125 patients in the much cited study of Murphy et $\mathrm{al}^{38}$ was excluded because they had not reached the age of 65 years.

In our study, we addressed these variables in a case-control study and found no differences in the reduction of joint space width.

There were no cases of subluxation in our own study and that of Cooperman et $\mathrm{al}^{10}$ which may explain the differences between these two studies and other longitundinal studies of dysplasia of the hip in adults. We have considered clinical and radiological factors but there is also mounting evidence of associated soft-tissue injuries contributing to the development of dysplasia of the hip.

It seem that the fibrocartilaginous acetabular labrum plays a key role in the pathogenesis of degeneration, especially in dysplastic hips, as does the meniscus to OA of the knee. Using radial MRI in 60 dysplastic hips, Kubo et al ${ }^{49}$ found that the acetabular labrum was larger in cross-sectional area than in 40 normal hips. Leunig et $\mathrm{al}^{8}$ assessed 23 young patients with hip pain by MRI arthrograms. Labral tears were confirmed intra-operatively in 18 patients, of whom 15 had dysplasia. In a study by Ganz et al ${ }^{24}$ describing a new periacetabular osteotomy for adult dysplasia, there was intra-operative evidence of associated labral detachment in $20 \%$ of cases. In a total of 170 hips with either mild or moderate dysplasia, McCarthy and Lee ${ }^{50}$ found labral tears in $122(72 \%)$ on arthroscopy. In another study McCarthy et $\mathrm{al}^{9}$ found labral tears in 241 of 436 younger patients (mean age 37 years) complaining of pain in the hip. Most tears $(86 \%)$ were in the anterior quadrant of the acetabulum and always at the articular junction of the labrum. McCarthy et $\mathrm{al}^{9}$ identified associated lesions of the acetabular articular cartilage in 273 patients $(62.6 \%)$, also notably in the anterior quadrant. There were highly significant associations between the presence of labral lesions and degeneration of the articular surface. They concluded that labral disruption and degeneration were integrated in the same pathogenesis of joint disease. In a poroelastic finite element model of the hip Ferguson et $\mathrm{al}^{51}$ demonstrated that removal of the labrum meant that solidon-solid contact stresses between articulating surfaces increased up to $92 \%$. Subsurface strains and stresses of the articular cartilage were higher without the labrum, and they found that the labrum provided resistance to lateral movement of the femoral head and enhanced stability and congruity of the joint.

The dysplastic acetabulum is characterised by the shallowness of its retaining cavity and the steepness of the cranial articulating roof which applies abnormally high stresses on the labrum. We suggest that labral tears or detachments are critical events in otherwise well-functioning dysplastic hips, accelerating degeneration. This may explain why subjects with verified dysplasia did not develop $\mathrm{OA}$ in the fifth and sixth decades of life. If labral injuries do not occur in non-subluxed, dysplastic hips, articular cartilage may remain intact throughout life. However, the labrum in these patients is more at risk of detachment than the labrum in normal hips. We expect that future experimental studies will provide further evidence of this relationship.

This study has received financial support from the Research Board of the University Hospital of Rigshospitalet, the Danish Medical Research Council, the Danish Rheumatism Association, the SAHVA Foundation, and Sygekassernes Helsefond.

No benefits in any form have been received or will be received from a commercial party related directly or indirectly to the subject of this article.

\section{References}

1. Wiberg G. Studies on dysplastic acetabula and congenital subluxation of the hip joint. Stockholm: P.A. Norstedt \& Söner, 1939:1-132.

2. Afoke NYP, Byers PD, Hutton WC. Contact pressures in the human hip joint. $J$ Bone Joint Surg [Br] 1987;69-B:536-41.

3. Bergmann F, Graichen F, RohImann A. Hip joint loading during walking and running, measured in two patients. J Biomechanics 1993;26:969-90.

4. Hadley NA, Brown TD, Weinstein SL. The effects of contact pressure elevations and aseptic necrosis on the long-term outcome of congenital hip dislocation. J Orthop Res 1990;8:504-13.

5. Legal H. Introduction to the biomechanics of the hip. In: Tönnis D, ed. Congenital dysplasia and dislocation of the hip. New York, etc: Springer-Verlag, 1987:26-56

6. Michaeli DA, Murphy SB, Hipp JA. Comparison of predicted and measured contact pressures in normal and dysplastic hips. Med Eng Phys 1997;19:180-6.

7. McCarthy JC, Busconi B. The role of hip arthroscopy in the diagnosis and treatment of hip disease. Can J Surg 1995;38 Suppl 1:13-17.

8. Leunig M, Werlen S, Ungersbock A, Ito K, Ganz R. Evaluation of the acetabular labrum by MR arthrography. J Bone Joint Surg [Br] 1997;79-B:230-4.

9. McCarthy JC, Noble PC, Schuck MR, Wright J, Lee J. The role of labral lesions to development of early degenerative hip disease. Clin Orthop 2001;393:25-37. 
10. Cooperman DR, Wallensten R, Stulberg SD. Acetabular dysplasia in the adult. Clin Orthop 1983;175:79-85.

11. Hasegawa Y, Iwata H, Mizuno M, et al. The natural course of osteoarthritis of the hip due to subluxation or acetabular dysplasia. Arch Orthop Trauma Surg 1992;111: 187-91.

12. Aktas S, Pekindil G, Ercan S, Pekindil Y. Acetabular dysplasia in normal Turkish adults. Bull Hosp Jt Dis 2000;59:158-62.

13. Auleley GR, Giraudeau B, Dougados M, Ravaud P. Radiographic assessment of hip osteoarthritis progression: impact of reading procedures for longitudinal studies. Ann Rheum Dis 2000;59:422-7.

14. Auleley GR, Duche A, Drape JL, Dougados M, Ravaud P. Measurement of joint space width in hip osteoarthritis: influence of joint positioning and radiographic procedure. Rheumatology 2001;40:414-19.

15. Buckland-Wright A. Radiographic assessment of osteoarthritis: comparison between existing methodologies. Osteoarthritis Cartilage 1999;7:430-3.

16. Croft P, Cooper C, Wickham C, Coggon D. Defining osteoarthritis of the hip for epidemiologic studies. Am J Epidemiol 1990;132:514-22.

17. Croft P, Cooper C, Coggon D. Case definition of hip osteoarthritis in epidemiologic studies. J Rheumatol 1994;21:591-2.

18. Croft P, Cooper C, Wickham C, Coggon D. Osteoarthritis of the hip and acetabular dysplasia. Ann Rheum Dis 1991;50:308-10.

19. Lanyen P, Muir K, Doherty S, Doherty M. Age and sex differences in hip joint space among asymptomatic subjects without structural change: implications for epidemiologic studies. Arthritis Rheum 2003;48:1041-6.

20. Lau EM, Lin F, Lam D, Silman A, Croft P. Hip osteoarthritis and dysplasia in Chinese men. Ann Rheum 1995;54:965-9.

21. Inoue $\mathbf{K}$, Wicart $\mathbf{P}$, Kawasaki $\mathbf{T}$, et al. Prevalence of hip osteoarthritis and acetabular dysplasia in french and japanese adults. Rheumatology (Oxford) 2000;39:745-8.

22. Smith RW, Egger P, Coggon D, Cawley MI, Cooper C. Osteoarthritis of the hip joint and acetabular dysplasia in women. Ann Rheum Dis 1995;54:179-81.

23. Yoshimura N, Campbell L, Hashimoto T, et al. Acetabular dysplasia and hip osteoarthritis in Britain and Japan. J Rheumatol [Br] 1998;37:1193-7.

24. Ganz R, Klaue K, Vinh TS, Mast JW. A new periacetabular osteotomy for the treatment of hip dysplasia: technique and preliminary results. Clin Orthop 1988;232:26-36

25. Siebenrock KA, Scholl E, Lottenbach M, Ganz R. Bernese periacetabular osteotomy. Clin Orthop 1999;363:9-20.

26. Søballe K. Pelvic osteotomy for acetabular dysplasia. Acta Orthop Scand 2003;74: 117-18.

27. Murphy SB, Millis MB, Hall JE. Surgical correction of acetabular dysplasia in the adult: a Boston experience. Clin Orthop 1999;363:38-44.

28. Schnohr $\mathbf{P}$, Jensen $\mathbf{G}$, Lange $\mathbf{P}$, Scharling $\mathbf{H}$, Appleyard $\mathbf{M}$. The Copenhagen city heart study: Österbroundersøgelsen: tables with data from the third examination 1991 - 1994. Eur Heart Journal 2001;3(Suppl H):1-83

29. Murray RO. The aetiology of primary osteoarthritis of the hip. Brit J Radio/ 1965;38: 810-24.

30. Stulberg SD, Harris WH. Acetabular dysplasia and development of osteoarthritis of hip. In: Harris WH, ed. The hip: Proc second open scientific meeting of the hip society. St Louis: CV Mosby, 1974:82-93.
31. Heyman $\mathbf{C H}$, Herndon $\mathbf{C H}$. Legg-Perthes disease: a method for the measurement of the roentgenographic result. J Bone Joint Surg [Am] 1950;32-A:767-78.

32. Tönnis $\mathbf{D}$. Normal values of the hip joint for the evaluation of $X$-rays in children and adults. Clin Orthop 1976;119:39-47.

33. Jacobsen S, Sonne-Holm S, Lund B, et al. Pelvic orientation and assessment of hip dysplasia in adults. Acta Orthop Scand 2005: in press.

34. Brinker MR, Lund PJ, Cox DD, Barrack RL. Demographic biases found in scoring instruments of total hip arthroplasty. J Arthroplasty 1996;11:820-30.

35. Mancuso CA, Salvati EA, Johanson NA, Peterson MG, Charlson ME. Patients expectations and satisfaction with total hip arthroplasty. J Arthroplasty 1997;12:387-96.

36. Bland J, Altman DG. Statistical methods for assessing agreement between two methods of clinical measurement. Lancet 1986;1:307-10.

37. Chitnavis J, Sinsheimer JS, Suchard MA, Clipsham K, Carr AJ. End-stage coxarthrosis and gonarthrosis: aetiology, clinical patterns and radiological features of idiopathic osteoarthritis. Rheumatology 2000;39:612-19.

38. Murphy SB, Ganz R, Muller ME. The prognosis in untreated dysplasia of the hip: a study of radiographic factors that predict the outcome. J Bone Joint Surg [Am]1995; 77-A:985-9.

39. Kellgren J, Lawrence JS. Radiological assessment of osteo-arthritis. Ann Rheum Dis 1957;16:494-502.

40. Spector TD, Cooper C. Radiographic assessment of osteoarthritis in population studies: whither Kellgren and Lawrence? Osteoarthritis Cartilage 1993;1:203-6.

41. Sun Y, Günther KP, Brenner H. Reliability of radiographic grading of osteoarthritis of the hip and knee. J Rheumato/ 1997;26:155-65.

42. Dougados M, Gueguen A, Nguyen M, et al. Radiographic features predictive of radiographic progression of hip osteoarthritis. Rev Rheum Engl Ed 1997;64:795-803.

43. Maillefert JF, Sharp JT, Aho LS, Dougados M. Comparison of a computer based method and the classicial manual method for radiographic joint space width assessment in hip osteoarthritis. J Rheumato/ 2002;29:2592-6.

44. Goker B, Sancak A, Arac M, Shott S, Block JA. The radiographic joint space width in clinically normal hips: effects of age, gender and physical parameters Osteoarthritis Cartilage 2003:11:328-34.

45. Danielsson L, Lindberg H. Prevalence of coxarthrosis in an urban population during four decades. Clin Orthop 1997;342:106-10.

46. Hoaglund FT, Steinbach LS. Primary osteoarthritis of the hip: etiology and epidemiology. J Am Acad Orthop Surg 2001;9:320-7.

47. Ingvarsson T, Hagglund G, Jonsson H, Lohmander LS. Incidence of total hip replacement for primary osteoarthrosis in Iceland 1982-1996. Acta Orthop Scand 1999;70:229-33

48. Oliveria SA, Felson DT, Reed JL, Cirillo PA, Walker AM. Incidence of symptomatic hand, hip, and knee osteoarthritis among patients in a health maintenance organization. Arthritis Rheum 1995;38:1134-41.

49. Kubo T, Horii M, Yamaguchi J, et al. Acetabular labrum in hip dysplasia evaluated by radial magnetic resonance imaging. J Rheumatol 2000;27:1955-60.

50. McCarthy JC, Lee JA. Acetabular dysplasia: a paradigm of arthroscopic examination of chondral injuries. Clin Orthop 2002;405:122-8.

51. Ferguson SJ, Bryant JT, Ganz $\mathbf{R}$, Ito $\mathbf{K}$. The influence of the acetabular labrum on hip joint cartilage consolidation: a poroelastic finite element model. J Biomechanics 2000:33:953-60 